\title{
Piribebuy, a capital mártir: história, historiografia e ideologia na Guerra no Paraguai
}

\author{
Piribebuy, the capital martyr: \\ history, historiography and ideology in \\ War of Paraguay
}

Mário Maestri*

Resumo: Piribebuy, terceira capital provisória do Paraguai, foi cercada e atacada pelas tropas aliancistas em 10-12 de agosto de 1869, durante a derradeira Campanha das Cordilheiras. Divergem as historiografias tradicionais paraguaia e brasileira sobre o desenvolvimento do ataque, que resultou em verdadeira mortandade entre os defensores da vila, e os sucessos posteriores a ele. A análise daquele fato histórico, a partir da documentação primária e dos relatos testemunhais de paraguaios e imperiais, permite aproximação dos sucessos objetivos e melhor percepção dos sentidos dos desvios das narrativas nacional-patrióticas destes últimos.

Palavras-chave: Piribebuy. Campanha das Cordilheiras. Guerra no Paraguai.

Abstract: Piribebuy, third provisional capital of Paraguay, was surrounded and attacked by aliancistas troops on August 10-12, 1869, during the last campaign of the Cordilleras. Traditional Paraguayan and Brazilian historiographies diverge not only on the attack development, which resulted in a massacre among the village defenders, true defenders of the village, but also on the events which followed it. The analysis of that historical fact, from the primary documentation and Paraguayans and Brazilian statements, enables to better approach those facts as well as the meanings of the national-patriotic narratives about them.

Keywords: Piribebuy. Campaing of the Cordilheiras. War of Paraguay.

\footnotetext{
* Doutor em História pela UCL, Bélgica, e professor do Programa de Pós-Graduação em História da UPF. Agradecemos a leitura da doutora Florence Carboni, da UFRGS. $<$ maestri@via-rs.net>.
} 
Em 27 de dezembro de 1868, a conclusão da batalha de Lomas Valentinas encerrou a campanha de Pykysyry com a destruição total do exército paraguaio. Francisco Solano López fugiu, por entre as tropas aliancistas, através do potrero Marmol, acompanhado por algumas dezenas de fiéis, aos quais se juntaram a seguir os troços do exército escapados à morte e ao aprisionamento.

Do acampamento de Cerro León, ao pé das Cordilleras, onde permaneceu por uns três dias, o mariscal marchou para a Cordillera de Ascurra (de los Altos), onde iniciou a formação de um novo corpo de exército, comporto por pequenos núcleo de veteranos e sobretudo por estropiados, por velhos, por adolescentes, por mulheres e até mesmo por crianças. (Centurión, 2010, p. 345).

A decisão do marquês de Caxias de dar a guerra por terminada, em janeiro de 1869, e partir de volta para a Corte e o hiato causado pela designação pelo Imperador de Louis Philippe Marie Ferdinand Gaston d`Orléans et Saxe-Cobourg et Gotha, conde d'Eu, seu genro, então com 27 anos, como comandante geral das tropas do império no Prata, permitiu que o mariscal consolidasse transitoriamente a autoridade do Estado sobre parte do interior do Paraguai, no primeiro semestre de 1869 , a partir de seu acampamento em Ascurra.

Com capital na vila de Piribebuy, desde 8 de dezembro de 1868, a república paraguaia das Cordilleiras estabeleceria-se com dificuldade e teria vida curta. A ocupação de Asunción, no início de 1869, e o domínio territorial aliancista exerciam atração patológica sobretudo sobre os segmentos proprietários de população vergada pelo peso do longo esforço bélico. No mínimo desde meados de 1867, a família López e núcleo substancial do aparato administrativo e das classes dominantes paraguaias conspiravam para o afastamento de Francisco Solano López e para rendição à Tríplice Aliança (Maestri, 2013a).

Mesmo nas áreas livres das Cordilleras, crescente número de homens e mulheres escondiam-se nas matas para escaparem à mobilização e procuravam a proteção das tropas imperiais. A partir de julho de 1869, à medida que se cerrou o cerco aliancista, cresceu a deserção, antes rara, entre as magras tropas paraguaias, mal-alimentadas, mal-armadas, mal-vestidas e desesperançadas na vitória (Rivarola, 2008-2009, p. 179; Vidaurreta, 1968, p. 18).

Entretanto, por ainda longo nove meses, alguns milhares de combatentes defenderam a independência nacional e o que ela significava socialmente para a grande população. Finalmente, a luta cessaria com 
a morte de Francisco Solano López, em Cerro Corá, em $1^{\circ}$ de março de 1870 (Cascudo, 1995, p. 114).

\section{Símbolos da resistência}

A memória paraguaia da resistência final contra as tropas aliancistas organiza-se sobretudo em torno de três grandes sucessos: o ataque e a ocupação da capital-mártir de Piribebuy, em 12 de agosto de 1869; a

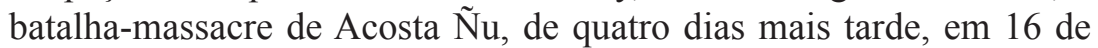
agosto, e a morte do Francisco Solano López, em $1^{\circ}$ de março do ano seguinte.

Publicada em fascículos semanais, desde 11 de abril de 2010, no diário Última Hora, de Asunción, a "novela gráfica" "Guerra contra la Triple Alianza: Vencer o Morir", do cartunista e ilustrador paraguaio Enzo Pertile, de 34 anos, de cem páginas, de forte sentido nacional-patriótico, aborda precisamente, em forma restritiva, "las batallas finales más emblemáticas" da guerra, nos três capítulos do álbum: "Vencer o Morir: La Batalha de Piribebuy; "Acosta Ñu", "Cerro Cora" (Pertile, s.d.).

Sobretudo no relativo às batalhas de Piribebuy e de Acosta Nu, a tradição histórica paraguaia dominante enfatiza a desesperada resistência do arremedo de exército paraguaio, formado por alguns veteranos e sobretudo velhos, adolescentes, crianças e mulheres mal-armados e o barbarismo sem travas dos poderosos exércitos aliancistas, com destaque para as tropas imperiais, então fortemente dominantes.

A proposta do comportamento sanguinário das tropas do Império nos nove meses finais da guerra criou a legenda do conde d'Eu, príncipe sádico e sanguinário. Essa versão histórica permitiu paradoxalmente o resgate relativo da atuação do marquês de Caxias, o grande responsável pela destruição dos exércitos paraguaios. No comics citado, de Enzo Pertile, quadro explicativo propõe: "En el tramo final de la contienda, el marques de Caxias se niega a seguir derramado sangre paraguaya [...]" (Pertile, s.d., p. 7).

A tradição histórica paraguaia das batalhas heróicas de Piribebuy e Acosta Nu arranca sua força no fato de simbolizarem os momentos finais da guerra, quando parte da população lutava desesperadamente contra a hecatombe nacional e social que a vitória da Tríplice Aliança materializaria. Jornadas derradeiras já sem vínculos com a discutível expedição paraguaia ao exterior que invadira às províncias de Corrientes, 
na Argentina, e do Mato Grosso e do Rio Grande do Sul, no Brasil. (Maestri, 2013b; Maestri, 2012a)

Realizadas sobretudo por tropas imperiais, a historiografia brasileira integrou aquelas operações organicamente à sua narrativa, como momentos de uma campanha militar em tudo homogênea, que defendia $o$ Império contra os desejos de conquista de ditador ambicioso e malévolo. (Maestri, 2008) Conhecida no Brasil como batalha de Campo Grande, o massacre de Acosta Nu seria objeto de célebre registro pictórico.

De volta de viagem de estudo na Europa, sob a sugestão direta do próprio Imperador, o pintor academicista Pedro Américo [18431905] emprendeu o quadro monumental "A Batalha de Campo Grande", concluído imediatamente após o conflito, em 1871. De enorme sucesso de crítica e de público, a obra glorifica os feitos bélicos imperiais e, sobretudo, a ação do genro do Imperador, que ocupa posição central na composição. Na construção da memória, a ficção rompia substancialmente com a realidade (Toral, 2001, p. 123).

\section{História, historiografia e ideologia}

As narrativas historiográficas dominantes paraguaias e brasileiras sobre as batalhas de Piribebuy e Acosta Nu divergem substancialmente. Porém, a análise daqueles sucessos históricos, a partir da documentação primária e dos relatos testemunhais de paraguaios e imperiais, permite aproximação dos fatos objetivos e melhor percepção dos sentidos dos desvios daquelas narrativas dos acontecimentos.

Publicada em 1922, a biografia hagiográfica El mariscal Solano López, de Juan Emiliano O’Leary (1879-1969), é a mais célebre narrativa nacional-patriótica paraguaia sobre a Guerra Grande [1865-1870]. Ela sintetiza e radicaliza exemplarmente a tradição histórica sobre o heroísmo paraguaio e os crimes aliancistas em Piribebuy.

A las cuatro de la mañana, las bandas de Piribebuy saludaran el amanecer $[\ldots]$ y poco después estallaron, a lo largo de nuestras líneas, los vivas acostumbrados a la Patria y al mariscal López. Los aliados se mantuvieron silenciosos [...]. Pero apenas acabó de aclarar iniciaron el terrible bombardeo [...]. Esto fue cruento como nunca. Los paraguayos se defendieron con estupendo heroísmo.

Segue O’Leary: 
Cuando sucumbieron todos nuestros soldados [sic], ocuparan sus puestos las mujeres. Y cuando terminamos nuestros proyectiles, cargamos con frutas de coco nuestros cañones... El enemigo encontró que la plaza había pasado a ser un cementerio. En el asalto habían sucumbido el general Mena Barreto y millares de invasores [sic]. El conde D'Eu se vengó [...] mandando degollar al jefe de Piribebuy, [...] y a casi todos los heridos. [...] ordenó que el hospital fuera incendiado, muriendo carbonizados algunos centenares de enfermos. (O'Leary, 1970, p. 276-78)

Essa versão segue dominando nos livros escolares. No Manual de Historia Paraguaya, de Luis G. Benitez, a batalha é descrita sinteticamente:

Piribebuy; Plaza defendida por el comandante Pedro Pablo Caballero, resistió heroicamente varios ataques brasileños; arrollados al fin, el 12 de agosto, el jefe brasileño conde d'Eu, ordeno el incendio del hospital de sangre y el degüello del comandante Caballero. (Benitez, 1970, p. 101)

Com a captura da terceira capital, Francisco Solano López abandou as defesas próximas no passo de Ascurra e retirou-se para o norte, começando, para essa versão romântico-patriótica dos sucessos, o que O'Leary definiria como sua verdadeira "Vía Crucis". Em fins de 1868, o mariscal já fora apresentado como o Cristo do povo paraguaio pelo sinistro e oportunista cônego Fidel Maíz, fortemente responsável pelo fuzilamento do bispo paraguaio Manuel Antonio Palacios, acusado de traição ao governo (Godoi, 1996, p. 73-95).

\section{Paraguai: a versão erudita}

Juan Crisóstomo Centurión [1840-1809] integrou o punhado de jovens paraguaios enviado para estudar na Europa pelo presidente Carlos Antonio López [1842-62], em 1858. Cinco anos mais tarde, em 1863, foi chamado de volta ao Paraguai. Desde então, participou do círculo de auxiliares próximos do presidente Francisco Solano López [1862-70], sem jamais alcançar posição de maior destaque na administração civil e militar paraguaia.

Homem de Letras, durante a guerra, entre outras funções, Centurión colaborou com o Semanario e foi diretor do Cabichui, acompanhando o mariscal até o derradeiro combate em Cerro Corá, já então com a 
patente de coronel ${ }^{1}$. Aprisionado pelos imperiais, foi enviado ao Brasil, de onde viajou para a França, Cuba, USA. Retornando ao Paraguai em 1878, destacou-se na vida cultura e política do país, ocupando o cargo de ministro de Relações Exteriores no governo do presidente Patricio Escobar [1886-90].

Centurión escreveu o livro Memorias o reminiscencias históricas sobre la Guerra do Paraguay, em quatro tomos, publicado apenas em 1944, décadas após sua morte, ocorrida em 1909. A obra goza de grande autoridade, devido à cultura, à informação e à seriedade do autor, apesar da permanente procura de autojustificação; de elogio patriótico da defesa nacional; de responsabilização de Solano López pelo drama.

$\mathrm{Na}$ descrição dos sucessos da guerra, a historiografia brasileira apoiou-se e apóia-se comumente em Centurión, em graus diversos. Em geral, também o fez para relatar o desenvolvimento dos acontecimentos em Piribebuy, mesmo rejeitando ou ignorando a denúncia dos crimes ali cometidos pelo Império, proposta pelo autor.

\section{Piribebuy segundo Centurión}

O pequeno povoado de Piribebuy, a pouco mais de $70 \mathrm{~km}$ a oeste de Asunción, encontrava-se na encosta de um cerro, cercados por colinas mais elevadas. Possuía humildes casas de tetos de palha e uma igreja colonial telhada. A vila era defendida por um fosso e trincheira de leiva, sob a forma de polígono irregular de 28 faces, de 2.422 metros de circunferência. Um córrego cortava Piribebuy, desaguando no arroio homônimo (Taunay, 2002, p. 134 et seq.).

No central, Centurión propõe que forças aliancistas, de vinte mil imperiais e argentinos e mais de trinta canhões, cercaram a vila em 10 de agosto de 1869, onde se encontravam 1.600 defensores, no geral "hombres mal armados, la mayor parte muchachos". No dia 11, após posicionar suas forças, o conde d'Eu teria intimado à rendição a Pedro Pablo Caballero. O comandante da vila teria respondido com palavras de aço, que o autor registra textualmente, como fez para tantos outros diálogos ou declarações: - "Estoy aquí para pelear, y si es necesario morir; pero no para rendirme" (Centurión, 2010, p. 393-94).

\footnotetext{
Sobre a imprensa patriótica paraguaia, ver, além de Antré Toral, já citado, o excelente trabalho de: SILVEIRA, Mauro César. A Batalha de Papel: A charge como arma na guerra contra o Paraguai. 2 ed. Florianópolis: UFSC, 2009.
} 
Na madrugada do dia 12, antes que iniciasse o bombardeio, sempre segundo Centurión, o conde d'Eu mandara novamente delegado intimar a Caballero "para que retirase del recinto del reducto a las mujeres y a los niños". Novamente Pedro Pablo Caballero respondera em forma altiva: "Decid a vuestro jefe que las mujeres y los niños están aquí seguros, y que él mandará en territorio paraguayo cuando no haya uno que lo defienda!" Destaque-se que mulheres e crianças eram boa parte das tropas defensoras da vila.

A seguir, "previo un recio bombardeo a la Plaza", teria iniciado o ataque, de resultados já certos, devido ao enorme desequilíbrio de forças - treze soldados aliancistas para cada paraguaio! "Y sin embargo la resistencia fue heroica y prolongada. Duró 5 horas!" - acrescenta Centurión. Segundo aquele autor, as tropas aliancistas teriam atacado em forma mais encarniçada pelo norte, posição que sabiam "guarnecida por cuerpos compuestos de muchachos debiles armados los más de escopetas de cazar y lanzas".

Como os demais atacantes, o general João Manuel Mena Barreto, montado "en un hermoso alazán", teria sido rechaçado "dos veces", retirando-se com suas tropas para reorganizar-se, para além do arroio Mboveví. Na terceira investida, a 500 varas [c. 550 metros] da trincheira, teria sido ferido mortalmente por uma bala de fuzil na "ingle", ou seja, na virilha. Transferido para uma cabana próxima, faleceu antes que o cirurgião chegasse.

Entrementes, os assaltantes romperam as defesas pelo sul, aprisionando, entre outros, Pedro Pablo Caballero e o chefe político da povoação, Patricio Marecos, conduzidos diante do "conde que habló con Caballero". Porém, ao saber que, mesmo não tendo morrido muitos assaltantes, falecera o general Mena Barreto, o comandante em chefe das tropas imperiais teria dito, apontando para os dois prisioneiros diante de si: “- Degüéllenlos a esos, ellos tienen la culpa!” Ordem que teria sido cumprida imediatamente.

Pedro Pablo Caballero teria sido degolado ao lado do cadáver do general sul-rio-grandense - ou o seu cadáver foi exposto junto a ele, mais tarde. Centurión refere-se a uma testemunha ocular, Asunción Gonzáles, que teria levantado o quepe do chefe paraguaio, constatando o corte ao pescoço, depoimento que afastaria a possibilidade de uma morte em combate.

Ao saberem da morte de Mena Barreto, a "soldadesca", "después de la toma de la Plaza, a pesar de los esfuerzos de los jefes, cometió muchos abusos, matando, o más bien asesinando, [...] a muchas 
gentes indefensas inútilmente". Portanto, Centurión isenta portanto parcialmente a oficialidade imperial de responsabilidade no massacre, realizado pela tropa indignada com a morte de Mana Barreto.

Centurión nega igualmente a responsabilidade do conde d'Eu e das tropas aliancistas no incêndio do hospital de sangue paraguaio, proposta pela tradição histórica paraguaia e pela historiografia nacional-patriótica, ao afirmar que teria ocorrido possivelmente devido ao bombardeio, ou seja, antes do assalto às trincheiras.

Para Juan Crisóstomo Centurión, a tragédia de Piribebuy, com mais de setecentos mortos em 1.600 defensores, devido a sua defesa gloriosa, foi uma "derrota heroica", que a "nación recordará siempre con gratitud y orgullo", ficando o nome do comandante Pedro Pablo Caballero e de todos os defensores "grabados con letras de oro en el templo de la inmortalidad".

Militar de carreira, Francisco Isidoro Resquín [1823-1882] integrou o comando da invasão do sul da província do Mato Grosso, participando a seguir com destaque de toda a campanha militar paraguaia. Aprisionado e levado ao Brasil, retornou ao Paraguai, sendo encarregado da organização do primeiro exército paraguaio após a guerra, durante o governo do presidente paraguaio Juan Bautista Gill [1874-1877].

O general Francisco Isidoro Resquín escreveu, entre outros, $L a$ guerra del Paraguay contra la Triple Alianza. Nessa obra sintética e menos segura do que as Memorias [...] de Centurión, acusa os oficiais aliancistas de "programa de crimen y extermínio". Ao abordar em forma imprecisa e telegraficamente o "Asalto a la Plaza de Piribebuy", que não presenciou, propõe igualmente defesa heróica, cinco horas de combate, "más de quinientos cadáveres enemigos", dez chefes e oficiais paraguaios degolados, além de Pedro Pablo Caballero, por ordem de "generales" (Resquín, s.d., p. 109).

\section{Relendo Centurión}

As Memorias [...] de Centurión tiveram alguns objetivos claros. Como já assinalado, entre eles, destacavam-se o registro do comportamento heróico do povo paraguaio na guerra, o que lhe teria assegurado espécie de vitória moral. Seu relato registra igualmente a busca de uma acomodação historiográfica mínima com o Brasil vitorioso, força então dominante na bacia do rio da Plata e no Paraguai.

Centurión tinha consciência da complexidade da redação de história geral do conflito: "La historia exige condiciones especiales de preparación 
de que carezco [...]." E ele não possuiria também o "tiempo" e "recursos para reunir y estudiar los datos necesarios" para tão complexa iniciativa. Portanto, apresentou seu trabalho como "memórias" e "ligeros apuntes para aydar al futuro historiador" (Centurión, 2010, p. 33.).

Entretanto, ao escrever suas reminiscências, Centurión redigiu história geral da guerra, servindo-se de suas memórias e das fontes que dispunha, que no geral não cita. Influenciado pela historiografia romântica, destacou o papel dos protagonistas que sintetizariam os sucessos e, sobretudo, personalizaram a resistência heróica da nação paraguaia. Para melhor animá-los, citou comumente suas declarações exemplares.

Ao se referir a Francisco Solano López e aos dirigentes políticos e militares paraguaios, o autor registra as declaração que ouvira ou sobre as quais fora informado de primeira mão, em geral durante o transcurso dos sucessos. Nos demais casos, reproduziu certamente a tradição. Tudo isso, décadas após os sucessos. Tratam-se de informações, portanto, influenciadas e determinadas pelos limites da memória, pelos fatos e sentimentos subsequentes, pelas necessidades da narrativa.

Ao igual que O'Leary, Centurión não se refere ao estupro das mulheres de Piribebuy pelas tropas vitoriosas, após os combates. É crível que um e outro não o fizessem por pudor nacional, para não confirmar tradição oral que desabonaria as mulheres vivas e mortas da povoação e o caráter marcial da resistência. No seu álbum, Enzo Pertile encena livremente longo suplício de Pedro Pablo Caballero, sofrido heroicamente, sem se referir a qualquer violência sexual contra as mulheres da vila.

\section{Centurión em Piribebuy}

Juan Crisóstomo Centurión não foi testemunha presencial do cerco e ataque a Piribebuy. Não parece ter tido igualmente acesso a uma importante documentação sobre o drama. Na sua descrição, estão ausentes dados importantes sobre os acontecimentos: a proporção de atacantes imperiais e argentinos - sobre os uruguaios, nem fala; a hora do início do bombardeio e do ataque; o número de canhões dos defensores; a ação dos sapadores imperiais que entulharam os fossos e destruíram os muros defensivos, etc.

Apesar dessas imprecisões, registra detalhadamente as palavras de Pedro Pablo Caballero, comandante militar da vila, ao rejeitar com palavras aceradas, por duas vezes, o oferecimento magnânimo de 
quartel do conde d'Eu que, ao menos nesse caso, teria seguido à risca a etiqueta que deveria reger a guerra entre "povos civilizados". Registra ainda literalmente a ordem verbal do genro do imperador para a degola imediata das duas autoridades máximas da vila.

Aquelas declarações enquadram-se perfeitamente na apresentação da defesa de Piribebuy como resistência heróica, registrada na necessidade do poderosíssimo exército aliancista de atacar três vezes o reduto, defendido durante cinco horas! Combate magnífico e heróico manchado pelo crime do príncipe francês e dos assaltantes desgostosos com a morte do general Mena Barreto. Crime perpetrado pelos soldados, segundo Centurión, em desobediência aos seus oficiais, como proposto.

\section{A versão nacional-patriótica brasileira}

$\mathrm{Na}$ versão tradicional da historiografia brasileira, o ataque a Piribebuy, em 12 de agosto de 1869, o primeiro grande combate sob o comando do conde d'Eu, em nada se distinguiu dos demais livrados durante a campanha, em correção e heroísmo. Na História da Guerra entre a Tríplice Aliança e o Paraguai, certamente o mais confiável trabalho da historiografia militar crítica brasileira, há apenas uma referência a que "a maior parte da guarnição era de adolescentes", nas quase quinze páginas dedicadas ao cerco e ataque a Piribebuy (Maestri, 2012b).

Nesse trabalho, de 1934, seu autor, o general Augusto Tasso Fragoso, nega o massacre de prisioneiros, sem praticamente se referir a tal possibilidade: "Como era natural, ficaram prisioneiros todos os que não pereceram na luta" (Fragoso, 1934, p. 273). Entretanto, os detalhes fornecidos sobre o combate pela documentação imperial são muito mais ricos do que os avançados por Juan Crisóstomo Centurión, por Francisco Isidoro Resquín e pela historiografia paraguaia.

Em 10 de agosto, 19 mil soldados imperiais, novecentos argentinos e mil uruguaios - a divisão oriental ficara vigiando a chegada de reforços inimigos - postaram-se diante da vila "circunvalada por extensa linha fortificada, que se estendia, irregular e mal traçada, por encostas de declive suave". Uma das primeiras iniciativas foi cortar a ligação telegráfica da povoação com Ascurra e a Caacupê (Fragoso, 1934, p. 266; Ordens do Dia,1877, p. 510; Taunay, 2002, p. 137).

A instalação de cinco baterias, com em torno de meia centena de canhões, em posição mais elevada, ao sul e a leste da vila, foi iniciada no dia 10 e concluída no dia 11. A artilharia encontrava-se 
em ótima colocação para o ataque, já que em posição superior à da vila de Piribebuy e de suas defesas (Cerqueira, 1929, p. 323; Taunay, 2002, p. 135-138). O ataque iniciou-se às 8:30, após duas horas de duro bombardeio. Segundo informe do brigadeiro José Luiz Mena Barreto, chefe do Estado Maior do Exército, os canhões "só cessaram seus tiros no momento conveniente ao assalto" (Menna Barreto, 1869, p. 570).

Paradoxalmente, as reminiscências presenciais e a documentação oficial sobre o ataque, inclusive a assinada pelo conde d'Eu, não registram o oferecimento de quartel, em 11 e 12 de agosto. Propostas que comprovariam a magnanimidade do conde e das tropas aliancista e confirmariam o patriotismo incondicional dos defensores, através da rejeição das mesmas. Destaque-se igualmente que tais oferecimentos eram feitos tradicionalmente por escrito, e não verbalmente por mensageiros, como proposto por Centurión. O oferecimento e a recusa teriam retrasado o assalto.

Em seu Diário do Exército, de 1870, o jovem oficial Alfredo de Taunay [1843-1899] não se refere ao oferecimento de quartel ou de retirada de mulheres e crianças, propostas por Centurión, que permitiu a Pedro Pablo Caballero reafirmar a decisão heróica de adultos, mulheres e crianças lutarem até a morte (Centurión, 2010, p. 393). Taunay confirma o horário do inicio do bombardeamento e do ataque e propõe fraca resposta dos 19 canhões e um morteiro paraguaios, que teria permitido que a artilharia aliancista se aproximasse para disparar com metralha sobre os defensores (Taunay, 2002, p. 136-7).

As 8:30, três colunas com tropas imperiais e argentinas passaram ao ataque, vanguardeadas por linhas de atiradores seguidas por sapadores levando carroças com pranchões de madeira, fardos de alfafa, escadas, ferramentas, etc. para facilitar a ultrapassagem dos fossos e a escalada das trincheiras em leiva. O trem da vanguarda atacante era completado por "contingentes do batalhão de engenheiros com as ferramentas precisas para acabar de abrir a brecha no parapeito que acobertava o inimigo" (Gastão de Orleans, 1869, p. 513).

Não há contradição essencial entre a narrativa imperial e a descrição imprecisa de Centurión sobre o número de tropas e a hora do início do bombardeio e do ataque. Entretanto, há radical oposição sobre a duração dos combates. Segundo os depoimentos presenciais e os informes oficiais imperiais, em um breve lapso de tempo, de 20 a 45 minutos, os primeiros infantes penetravam em Piribebuy, por fenda aberta, inicialmente, na parte sul das defesas. 


\section{Vitória Quase Imediata}

O futuro general Dionísio Cerqueira participou do ataque. "O combate durou pouco - talvez menos de meia hora. Toda a guarnição inimiga caiu em nosso poder" (Cerqueira, s.d, 327). O informe do conde d'Eu ao ministro e secretario d'Estado dos Negócios da Guerra, de 3 de setembro de 1869, tratando daqueles e de outros sucessos, era cabal sobre a rapidez da operação. Também nele não há registro dos três ataques e das duas propostas de quartel de retirada de mulheres e crianças.

Ao referir-se à coluna dirigida pelo malogrado Mena Barreto, o conde lembrava sobre os batalhões que a compunham: "[...] foram os primeiros que carregaram sobre aquele lado do entrincheiramento inimigo e nele quase imediatamente penetraram". Ao se referir à coluna que avançava a sua direita, propôs ter ela atingido "com incrível velocidade o entrincheiramento, e, transpondo o fosso, já fincara no cume do parapeito a sua bandeira desfraldada" (Gastão de Orleans, 1869 , p. 514).

Ainda mais explícito, o conde d'Eu afirmou que o combate sobre a trincheira daquele destacamento prolongara-se "por oito minutos", penetrando a seguir as tropas "no recinto". Quanto à coluna argentina, ela vencera "a trincheira, poucos instantes depois do batalhão brasileiro". Invadido o perímetro, a cavalaria atuara imediatamente, dizimando os combatentes desorganizados dentro e "fora do entrincheiramento", quando tentavam escapar (Gastão de Orleans, 1869, p. 514).

Em relatório para o Conde, escrito imediatamente após o combate, em Piribebuy, em 12 de agosto, o general José Luiz Mena Barreto, chefe do estado maior, anotou também um único e exclusivo ataque, rapidamente concluído. "[...] foi tal o entusiasmo e o denodo com que carregaram as nossas forças, que o inimigo, tendo dado à aproximação delas a primeira descarga de artilharia, não pôde dar [uma] segunda", sem tempo hábil para "carregar de novo seus canhões" (Menna Barreto, 1869, p. 552).

Segue José Luís Mena Barreto:

Entretanto, o nutrido fogo de fuzilaria [...], impedindo o trabalho dos sapadores, demorou por algum tempo o assalto; mas o esforço e a coragem dos assaltantes venceram os obstáculos que se lhes apresentaram, e em menos de um quarto de hora caiu em nosso poder a terceira capital do inimigo com tudo quanto continha. (Menna Barreto, 1869, p. 552) 
O responsável da Comissão Imperial de Engenheiros, ao dar parte, em Caacupé, em 15 de agosto, dos trabalhos daqueles especialistas durante o assalto a Piribebuy, relata que, "as galeras", partindo ao assalto atrás das "colunas" de infantes, aproximaram-se das defesas a "galope" e os "engenheiros" a "marche marche" [o mais rápido passo militar]. Sendo "entulhados com a presteza possível" os pontos designados, os assaltantes teriam penetrado em "menos de 15 minutos" no reduto, acompanhados a seguir da "cavalaria" que, carregando, completou a "vitória" (Galvão, 1869, p. 554 e 558).

Tão rápida fora a vila "assaltada e vencida" que o serviço sanitário desdenhara a proposta inicial de localizar o hospital de sangue aliancista em uma moradia na "vizinhança da povoação", em favor do estabelecimento do mesmo em uma casa "dentro da mesma povoação"! (Secretaria do Corpo de Saúde do Exército, 1869, p. 563) Ou seja, os poucos feridos das tropas assaltantes foram tratados dentro do reduto inimigo, já em mãos aliancistas.

Em seu Diário [...], Taunay foi ainda mais explícito sobre a cronologia dos combates, propondo que, após o assalto às defesas, as tropas "logo tocaram das trincheiras a gente que as defendia". Ele propõe horário preciso para a conclusão do confronto: "Penetrando então, por duas aberturas, a $2^{\mathrm{a}}$ e a $3^{\mathrm{a}}$ Divisões de Cavalaria, tornou-se impossível a resistência, que, às 9 horas, achava-se na verdade completamente sufocada." (Taunay, 2002, 137).

Portanto, após as tropas penetrarem às " 8 horas e quarenta e cinco minutos" em Piribebuy, o fim dos combates teria sido alcançado quinze minutos mais tarde! Ou seja, o ataque durara das 8:30 às 9:00 horas. Ou seja, não mais do que meia hora! Em verdade, não houver resistência, tendo sido os defensores total e plenamente desbaratados, sem delongas, pelo assalto avassalador das tropas inimigas.

\section{Os três assaltos}

Em Maldita guerra, talvez procurando diminuir o desequilíbrio entre as versões paraguaia e imperial sobre a duração do ataque, Francisco Doratioto propõe os quinze minutos da versão brasileira como tempo gasto na superação das defesas e duas horas no interior do reduto, para a conclusão dos combates: “[...] as colunas atacantes avançaram sobre a vila e entraram nas trincheiras paraguaias em quinze minutos, embora o combate se estendesse por cerca de duas horas mais." 
O paradoxal é que, ao propor arbitrariamente, por um lado, quinze minutos para o assalto às trincheiras, e aceitar, por outro, a proposta de Centurión de três ataques, Doratioto coloca os assaltantes na impossível obrigação de realizarem em cinco minutos cada percurso de ida e volta, das suas posições até as trincheiras, sem interrupção, incluindo nesse tempo os respectivos combates! (Doratiotto, 2002, p. 408).

A rápida vitória era o resultado mais do que previsível. $\mathrm{O}$ ataque a Piribebuy, por três colunas de milhares de soldados treinados e poderosamente armados, era literalmente indefensável. Os 2.422 metros de circunferência da trincheira não permitiam postar, a cada dois metros, mais do que um homem, ou uma mulher, ou um adolescente, ou uma criança, mal treinados e mal armados! E possivelmente nem isso, após o duro bombardeio (Ordens do Dia, 1877, p. 557).

Vimos que Taunay registrou o quase silêncio da artilharia paraguaia, desmontada pelo bombardeio ou pouco inativa por falta de munição ou artilheiros competentes, o que voltaria a repetir-se, a seguir, na batalha de Acosta Ñu. Dionísio Cerqueira confirma tal realidade: "Os paraguaios defendiam-se bravamente, mas o seu armamento não auxiliava. Das trincheiras choviam sobre nós projéteis de todo o gênero. [...] José Thomas Carneiro da Cunha ficou com a cara quebrada por um tijolo [...]" (Cerqueira, 1929, p. 325).

\section{A morte do brigadeiro}

Toda a documentação oficial do Império confirma igualmente que o general João Manuel Mena Barreto, que comandava a coluna que atacou a vila pela esquerda, fora morto no início dos combates, com tiro na virilha, ainda montado, e não como propõe Centurión, no início do terceiro assalto, que jamais teria ocorrido. Dionísio Cerqueira propõe que foi alvejado já "no fim" dos combates, "quando se ouvia o toque de cessar fogo [...]” (Cerqueira, 1929, p. 327).

João Manuel nasceu em 1824, em Porto Alegre, no Rio Grande, onde a família Mena Barreto possuía importantes estâncias. Lutara na Guerra Farroupilha, desde 1842, ao lado dos imperiais; participara das invasões do Uruguai, em 1852, em 1854 e da defesa de São Borja diante dos paraguaios e do cerco de Uruguaiana, em 1865. No Paraguai, lutara em Avaí e Lomas Valentinas. Já em setembro de 1869, o governo imperial concedeu pensão de 600 mil-réis para cada uma das suas filhas (Ministério dos Negócios da Guerra, 1869, p. 501). 
As Memórias de Alfredo Taunay foram editadas postumamente, em 1946, quando já se completara o centenário de seu nascimento, como exigira. No livro, informou dado romântico, mas pouco marcial, sobre a morte de Mena Barreto, impossível daquele autor registar no seu Diário [...], publicado em 1870: "Caiu do cavalo nos braços de valente china, que o acompanhava sempre, até no meio dos mais rijos combates, o que de certo não era nada regular mas tem grandeza." (Taunay, s.d., p. 346.). O general foi enterrado provisoriamente no interior da Igreja de Piribebuy, no dia 13, ao "lado direito do altar-mor", posição reservada aos mais destacados membros da sociedade (Taunay, 2002, p. 138).

No Diário [...], Taunay refere-se a "700 cadáveres contados", após o combate, "entre os quais os do Tenente-Coronel Caballero, comandante da praça e do Major Lopes", além de mais de trezentos feridos e oitocentos prisioneiros. As tropas aliancistas teriam tido apenas 69 mortos! (Fragoso, 1934, p. 276) O conde d'Eu confirma os dados: "[...] contaram-se perto de 700 cadáveres paraguaios e mais de mil e cem prisioneiros entre feridos e sãos" (Ordens do Dia, 1877, p. 518).

\section{O que aconteceu após os combates?}

As versões imperiais e paraguaias divergem também quanto aos sucessos posteriores à vitória. Como vimos, Centurión propôs que, ao saber da morte de Mena Barreto, o conde d'Eu ordenara pessoalmente a degola das duas principais autoridade da vila e que os soldados, indignados com a notícia, a revelia da vontade de seus oficias, teriam se dado à execução de rendidos e prisioneiros.

Centurión não toca a questão do estupro das mulheres de Piribebuy, registrada pela memória e retomada pela tradição histórica paraguaia. Como também assinalado, inocenta o conde d'Eu e os aliancistas pelo incêndio do hospital de sangue paraguaio, com a morte de centenas de feridos, doentes e atendentes. Para ele, o sucesso fora possivelmente devido à bomba lançada desde "las posiciones inimigas", durante os combates. (Centurión, 2010, p. 394).

A documentação militar oficial imperial não registra traços de degola e de estupros. Mesmo anotando em seu Diário [...], de 1870, os setecentos mortos e "300 e tantos feridos", desequilíbrio anormal dos primeiros em relação aos segundos, Taunay não cita violências contra rendidos. Anota apenas que a "maior parte da guarnição era de adolescentes" e a "tenacidade na defesa", com mulheres armadas de "vidros e pedras" (Taunay, 2002, p. 138). Reafirma as "altas qualidades" 
de caridade" da "oficialidade" aliancista que teria posto a mão no bolso para socorrer os "prisioneiros" de López libertados. (Taunay, 2002, p. 137).

Em Recordações de guerra e de viagem, narrativa de vocação biográfica, publicada por seu filho, meio século após os sucessos, quando a maioria dos protagonistas já se encontrava morta, Taunay apresenta versão sobre a degola que se aproxima já da sugerida por Centurión e pela tradição paraguaia. Essas páginas, com escassas modificações, fizeram parte das Memórias do visconde, publicadas por sua vontade, como vimos, décadas após sua morte (Taunay, s.d., p. 12).

Nas Recordações, já não mais nos panos de escriba do conde d'Eu, Taunay vai além dos soldados-adolescentes que anotara no Diário [...], referindo-se a crianças de "dez anos, e menos ainda, morta[s] quer de bala[s], quer lanceada[s] junto às trincheiras" que ele, "contendo a custo as lágrimas" "percorrera a cavalo". E, a seguir, foi elucidativo sobre as execuções, apesar de manter a contensão. "Faziam-se prisioneiros, no momento em que eu passava; e, entre parênteses, ainda se matava, bem inutilmente, aliás, salvei um dos desgraçados, que iam ser degolados [...]." (Taunay, 2008, p. 58; 2002, p. 138).

Escrevendo décadas após os fatos, Dionísio Cerqueira registrou igualmente em forma indiscutível, também através da proposta de sua intervenção providencial, o massacre que se seguiu ao ingresso das tropas em Piribebuy. "Em poucos instantes, as nossas forças galgavam as trincheiras, invadiam o terrapleno e investiam, aos bandos, contra os paraguaios, que se retiraram em debandada, mas ainda pelejando."

Com o pudor de velho militar, registra sem alardear a morte que dera a combatente adolescente sem treinamento: "Fez-me frente, com uma lança, um rapazinho, que parecia forte; aparei o golpe, respondi e passei adiante." Segue Cerqueira: "Logo depois, um soldadinho paraguaio, que não podia ter mais de doze anos, corria, todo ensangüentado, para o meu lado, acossado por um soldado nosso [...] e já o ia alcançando, quando ele se abraçou comigo, implorando que o salvasse."

A informação que fornece confirma o massacre e desmente a proposta de Centurión que ele se dera contra a vontade da oficialidade imperial e argentina. Relata o futuro general: "Mal tive tempo de conter o seu perseguidor. Nesse momento, passava por mim, a trote largo, o distinto camarada capitão Pedra, que gritou: - Mata. - Não - disse eu É um prisioneiro, uma pobre criança e hei de defendê-lo." (Cerqueira, 1929, p. 326). 
Dionísio Cerqueira escreve sobre sucessos ocorridos havia longas décadas, após a publicação das Recordações de Taunay. Talvez sequer ele pudesse então dizer com certeza se o relato edificante realmente ocorrera como propunha ou fora re-elaboração inconsciente de lembrança de fato terrível ao qual gostaria de se ter oposto, quando escrevia ou na época do ocorrido. Porém, seu depoimento confirma a proposta de Taunay da degola, no seu caso, de soldado-criança, numerosos entre os defensores.

\section{A guerra também é uma festa}

Juan Crisóstomo Centurión recrimina a Solano López por não evacuar Piribebuy, expondo à perda inevitável de tropas, de armas e de riquezas. A defesa impossível da capital facilitou entretanto a retirada do mariscal. Após os combates, os aliancistas depararam-se extasiados com "grandes depósitos de melaço, polvilho, milho, erva-mate"; os "arquivos da República, importantes quantidade de prata cunhada e de igreja, livros, papéis, mobílias" (Centurión, 2010, p. 394). Na residência da madame Lynch havia "trastes ricos, porcelanas, camas douradas", "vinhos delicados e licores", além de prata amoeda (Taunay, 2008, p. 59; 2002, p. 137).

O conde d'Eu comunicou ao governo imperial o botim encontrado: “[...] todo o arquivo publico da República do Paraguay até o ano de 1868, inclusive a correspondência secreta de seu ministério de estrangeiros. [...] depósitos de farinha, erva mate, vinhos da Europa em grande quantidade, caixões com roupa, diferentes objetos de prata lavrada, numerário de diversos países, uma soma de papel moeda do Brasil", além de "oficina de concertar armamento, parte do material de uma tipografia e de uma estação telegráfica" (Ordens do Dia, 1877, p. 518).

O príncipe consorte não se referiu minimamente ao saque. No Diário [...], de 1870, Taunay anotou, en passant, "saque" que teria sido "rapidamente comprimido" (Taunay, 2002, p. 137). Nas Recordações, publicadas décadas após os sucessos, é já mais comedido sobre a repressão ao saque: "Tomado Peribebuí, e abafada qualquer resistência, houve o seu saquezinho [sic], apesar dos esforços para reprimi-lo". Apesar dos propostos esforços, escreveu que os soldados "entravam nas casas e saíam com muitos objetos, que iam tomando violentamente ou apanhando pelo chão" (Taunay, 2008, p. 58-9).

Definitivamente, não se tratara de desmando rapidamente reprimido pela oficialidade: "Não poucos soldados, quando penetrei na morada de Lynch, passaram por perto de mim, levando em panos e mantas grande 
porção dessa prata, quando podiam carregar." Apenas os ricos objetos que escaparam ao saque teriam sido entregues à "repartição fiscal" (Taunay, 2008, p. 59). O saque seria possivelmente também forma dos praças de financiarem suas necessidades durante a guerra, devido aos habituais e programados atrasos dos soldos da tropa (Rebouças, 1973, p. 154).

Dionísio Cerqueira lembra-se igualmente das enormes riquezas encontradas em Piribebuy, com destaque para os "vestidos de madame Lynch, de seda e veludo, bordados a oiro." Recorda-se igualmente dos víveres, do "excelente vinho angarrafado", da "profusão" de "charutinhos paraguaios muito gabados". Sobre esses e outros bens, afirma, sem peias, referindo-se certamente a soldados e oficiais: "Fez-se mão baixa sobre tudo" (Cerqueira, 1929, p. 329).

Talvez nada fixe melhor o sentimento dominante dos soldados sobre os bens dos vencidos que se encontravam ao alcance de suas mãos, do que o registro inocente de Taunay de sua participação no saque. $O$ futuro visconde lembra que bebeu com seus próximos, sem travas, "vinhos de excelente qualidade, sobretudo caixas de champagne, de indiscutível procedência, e das melhores marcas". Sugere que provinham diretamente da cave de Francisco Solano López (Taunay, 2008, p. 60). No frente de batalha, essas bebidas, vendida por ávidos negociantes, alcançavam valores altíssimos, mesmo para os oficiais (Silva, 1924, p. 32 et passim).

Em suas Memórias, Taunay lamenta apenas a "bem pequena" "quantidade" das bebidas excelentes, o que contrasta com a afirmação do conde de que havia bebidas de qualidade "em grande quantidade". (Taunay, s.d., p. 349) Taunay lembra ainda: "Em Peribebuí, apanhei, entre vários livros que pertenciam a Francisco Solano López, o segundo volume de um D. Quixote do imortal Cervantes, edição de luxo, em espanhol, jornada [sic] de boas gravuras." Uma obra na época certamente de elevado valor! (Taunay, 2008, p. 60).

\section{Paraguaias carinhosas}

Não há registro do estupro geral das mulheres de Piribebuy na documentação militar oficial do Império. Vimos que O'Leary e Centurión não se referem a tal sucesso. No trabalho citado, o general Resquín lembra a "bárbara matanza y crueles martírios" a que foram submetidos os "prisioneiros", talvez um registro indireto e implícito das violências que sofreram as mulheres de Piribebuy (Resquín, s.d., p. 109).

Paradoxalmente, é a própria memorialística imperial que confirma a proposta da tradição paraguaia sobre aquelas violências contra as 
mulheres e sugere a relativa normalidade com que eram vistas nas tropas aliancistas e praticadas por elas. Dionísio Cerqueira refere-se em forma humorística ao ataque às mulheres após os combates: "Ao passar debaixo de um laranjal, vi mulheres escondidas na ramalhada, transidas de pavor, algumas com os filhos nos braços. Em baixo, soldados convidavam-nas a descer, e elas, como o galo da fábula, desconfiavam das lábias das velhas raposas, que aliás, é de crer, não tinham desejos sanguinários." Havendo apenas desejos libidinosos, desta vez, o jovem não teria interferido! (Cerqueira, 1929, p. 327).

A seguir, o futuro general registra indiscutivelmente a banalização do estupro das mulheres paraguaias por soldados e oficial das tropas aliancistas, ao reproduzir canção entoada, mais tarde, por José da Rocha, soldado do batalhão de engenheiros e artista profissional na vida civil, em espetáculo assistido pelo conde d'Eu, para a excitação "do conspícuo auditório de generais e chefes".

Dionísio Cerqueira transcreve a canção que descrevia o que acontecera e arrolava o que fora encontrado em Piribebuy: "surrão de mate, cheio de patacão"; soldados paraguaios defendendo-se jogando "pedras"; "melado", "charuto", "garrafas" de bebidas alcoólicas, etc. Certamente relembrando as agradáveis recordações dos sucessos magníficos quando e após o combate, o futuro general apresenta banalmente os versos terríveis do soldado-trovador:

Tudo é poesia,

Poesia fina.

Dentro do Arreducto

Não faltava china.

(Cerqueira, 1929, p. 330)

Comentando a canção, que reduzia toda mulher paraguaia à qualidade de china, Cerqueira lembra que, algumas "mulheres durante o assalto, nas trincheiras, atiravam-nos pedras e outros projetos." E conclui, irônico e malicioso: "Quem as visse depois, não acreditaria que fossem as mesmas, tal a amabilidade e cordura." Esquecia que a cooperação carinhosa era certamente obtida pelos vencedores com o argumento do punhal no cinto, com o direito de usá-lo.

\section{A guisa de conclusão}

A precisão e a concordância dos diversos depoimentos presenciais realizados quando e após o assalto, assim como a variada documen- 
tação oficial sobre ele, não deixam espaço para dúvidas. Não houve a gloriosa resistência proposta por Centurión, que teria exigido três assaltos e cinco horas de combates para vencer as defesas, e os "más de quinientos cadáveres enemigos" registrados por Resquín. O escassos número de vítimas fatais entre as tropas aliancistas registrava já a facilidade da conquista - apenas 69 mortos! (Fragoso, 1934, p. 274).

Teria sido ataque, sem oferecimento de quartel, de tropas maciçamente superiores, resolvido em não muito mais de meia hora! Os relatos aliancistas sobre a valentia dos defensores foram possivelmente declarações retóricas necessárias para escamotear o verdadeiro massacre sobretudo de velhos, adolescentes, crianças e mulheres mal-armados e mal-treinados, após a superação das rústicas defesas da pequena capital paraguaia.

Os depoimentos de oficiais imperiais não deixam igualmente dúvidas sobre a ampla execução, em parte por degola, de adultos e, talvez, sobretudo, de adolescentes e de crianças, devido a apresentarem menor resistência. Acontecimentos já sugeridos pelo enorme desequilíbrio entre o número de mortos e o de feridos, inesperado sobretudo em um ataque e vitória tão rápidos.

Não é improvável a ordem direta dada para que Pedro Pablo Caballero e o chefe político da vila fossem executados, mesmo sendo certamente criação da tradição popular as palavras usadas pelo conde, transcritas por Centurión. Trata-se porém de fato que exige maior investigação e comprovação documental, sendo talvez mais verossímil que as duas autoridades tenham sido executadas logo após serem presas, pelas próprias tropas aliancistas, sob as ordens ou cumplicidade dos oficiais.

Se a execução de prisioneiros, ainda mais adolescentes e crianças, era hábito não excepcional, ela sofreria sanção ou constrangimento moral, nem que fosse formal, após o calor dos combates. Matar prisioneiros era prática definitivamente rejeitada pela etiqueta e pelas práticas militares oficiais. Tanto que os futuros visconde de Taunay e o general Dionísio Cerqueira preocuparam-se em registrar suas oposições àqueles sucessos, que é difícil definir se foram reais ou imaginárias.

Paradoxalmente, o saque e, sobretudo o estupro de mulheres das populações inimigas seriam práticas tidas como quase normais, entre as tropas e a oficialidade, no curso das operações em território paraguaio. 


\section{Referências}

BENITEZ, Luis G. Manual de Historia Paraguaya: para el primer curso del ciclo básico. Asunción: El Arte, 1970.

CASCUDO, Luiz Câmara López do Paraguay. Mossoró: Fundação Vingt-Un Rosado, 1995. [Natal: A República, 1927; edição fac-similar]

CENTURIÓN, Juan Crisóstomo. Memorias o reminiscencias históricas sobre la guerra del Paraguay. Asunción: El Lector, 2010.

CERQUEIRA, General Dionísio. Reminiscências da campanha do Paraguai. (18651870). 2. ed., rev. Rio de Janeiro: F. Briguiet, 1929.

DORATIOTTO, Francisco F. Monte oliva. Maldita guerra: Nova história da guerra do Paraguai. São Paulo: Companhia das Letras, 2002.

FRAGOSO, Gal. Tasso. História da guerra entre a Tríplice Aliança e o Paraguai. Rio de Janeiro: Imprensa do Estado Maior do Exercito, 1934. Vol. 4.

GALVÃO, Coronel Rufino Eneas Gustavo, chefe da Comissão de engenheiros junto ao comando em chefe. Acampamento em marcha na villa de Caacupé (republica do Paraguay), 15 de agosto de 1869. ORDENS DO DIA, 1877, ob. cit.

GASTÃO DE ORLEANS. Comandante em chefe. Comando em chefe de todas as forças brasileiras em operações na republica do Paraguay. Quartel General em Caraguatahy, 3 de setembro de 1869. ORDENS DO DIA, ob. cit.

GODOI, Juan Silvano. El fusilamiento del Obispo Palacios y los tribunales de sangre de San Fernando. Documentos históricos. Asunción: El Lector, 1996.

MAESTRI, Mário. A Guerra Contra o Paraguai: História e Historiografia: Da instauração à restauração historiográfica [1871-2002]. Nuevo Mundo/Mundos Nuevos, 2008. Disponível em: <http://www.nuevomundo.revues.Org/55579>.

MAESTRI, Mário. O Plano de Guerra Paraguaio em uma Guerra Assimétrica: 1865. Revista Brasileira de História Militar, [2013b, no prelo]. <www.historiamilitar.com.br>

MAESTRI, Mário. O singular relato do cônego João Pedro Gay sobre a Invasão Paraguaia da Província de São Pedro do Rio Grande do Sul. Estudios Historicos - CDHRP, Uruguay, año IV, n. 9, dic. 2012a. ISSN: 1688-5317. <http://www.estudioshistoricos. org/>.

MAESTRI, Mário. Tasso Fragoso e a Guerra da Tríplice Aliança: História e ideologia. O Olho da História, Salvador, n. 18, jul. 2012b. Disponível em: <www.olhodahistoria. org/index.php>.

MAESTRI, Mário. Tribunais de Sangue de San Fernando: o sentido político-social do terror lopizta. Revista História: Debates e Tendências, PPGH da UPF, Passo Fundo, [2013a, no prelo].

MENNA BARRETO, brigadeiro José Luiz. No comando do $1^{\circ}$ Corpo de Exercito, Quartel-General, em Marcha Junto a Caacupé, 15 de agosto de 1869. ORDENS DO DIA, ob. cit.

MENNA BARRETO, José Luiz, chefe do Estado Maior. Perebebuy, 12 de agosto de 1869. ORDENS DO DIA, ob. cit.

MINISTÉRIO dos Negócios da Guerra. Rio do Janeiro, em 5 de outubro de 1869. ORDENS DO DIA, 1877, ob. cit. 
O’LEARY, Juan E[miliano]. El Mariscal Solano López. 3. ed. Asunción: Paraguay, 1970. [1. ed. 1922; 2. ed. 1925, rev., aum.].

ORDENS DO DIA, Exército em operações na Republica do Paraguay. Sob o commando em chefe de todas as forças, de sua alteza o Senhor príncipe marechal do Exercito Luiz Felipe Fernando Gastão de Orleans, Conde d'Eu. Comprehendendo as 1 a 47. 1869 a 1870. Re-impressa por ordem do Governo. Rio de Janeiro: Francisco Alves de Souza, 1877.

PERTILE, Enzo. Guerra contra la Triple Alianza: vencer o morir. Asunción: Servi Libro, [s.d.].

REBOUÇAS, André. Diário da guerra do Paraguai (1866). São Paulo: Instituto de Estudos Brasileiro, 1973.

RESQUÍN, Francisco Isidoro. La guerra del Paraguay contra la Triple Alianza. Asunción: El Lector, s.d.

RIVAROLA, Milda. La Resistencia a la Guerra Grande. Estudios Paraguayos, U.C., Departamento de Ciencias Sociales, Centro de Estudios Antropológicos, Asunción, v. 26/27, 1 y 2, p. 179-189, 2008-2009. <www.portalguarani.com/obras_autores detalles.php?id_obras $=13571>$.

SECRETARIA DO CORPO DE SAÚDE DO EXÉRCITO. Acampamento em marcha em Caraguatahy, 26 de agosto de 1869. ORDENS DO DIA, 1877, ob. cit.

SILVA, José Luiz Rodrigues da. Recordações da campanha do Paraguay. São Paulo: Melhoramentos, [1924].

SILVEIRA, Mauro César. A batalha de papel: a charge como arma na guerra contra o Paraguai. 2. ed. Florianópolis: UFSC, 2009.

TAUNAY, A. Recordações de guerra e de viagem. 2. ed. Brasília: Senado Federal, 2008.

TAUNAY, Alfredo D’Escragnolle, Visconde de. Diário do Exército, campanha do Paraguai (1869-1870). Rio de Janeiro: Biblioteca do Exército, 2002.

TAUNAY, Alfredo D’Escragnolle, Visconde de. Memórias. São Paulo: Melhoramentos, s.d.

TORAL, André. Imagens em desordem: a iconografia da Guerra do Paraguai (18641870). São Paulo: Humanitas/FFLCH/USP, 2001.

VIDAURRETA DE TJARKS, Alicia. Al Margen de la Guerra del Paraguay. Memoria Academica. Trabajos y comunicaciones, 1968, 18. <www.memoria.fahce.unlp.edu.ar/ art_revistas/pr.1060/pr.1060.pdf>. 